\title{
Czy niepełnosprawność zawsze znaczy to samo? - analiza wpływu kultury na rozumienie niepełnosprawności
}

Maria Stojkow

https://orcid.org/0000-0002-8410-3730 AGH, Akademia Górniczo-Hutnicza w Krakowie 


\section{Streszczenie}

Badanie niepełnosprawności w perspektywie etnicznej staje się niezwykle istotne w dobie migracji na szeroką skalę. Ludzie opuszczają swe miejsca zamieszkania nie tylko w poszukiwaniu lepszego, bardziej dostatniego i spokojnego życia, ale również ze względu na konflikty zbrojne i katastrofy klimatyczne. Stają się nie tylko migrantami zarobkowymi, ale uchodźcami wojennymi, politycznymi czy klimatycznymi. Do kraju osiedlenia docierają często osoby z niepełnosprawnościami. Docierają do społeczeństw, gdzie ich niepełnosprawność jest często inaczej rozumiana niż w kraju pochodzenia, stykają się z nowym rozumieniem niepełnosprawności, reprezentowanym między innymi przez instytucje. Coraz więcej migrantów z różnych części świata dociera również do Polski, zatem potrzeba badania różnic kulturowych w postrzeganiu i radzeniu sobie z niepełnosprawnością wydaje się dziś koniecznością. Dodatkowo warto zwrócić uwagę na występujące w wielu regionach nakładanie się różnych wymiarów wykluczenia społecznego i dyskryminacji, których doświadczają osoby niepełnosprawne pochodzące $\mathrm{z}$ innych kręgów kulturowych lub z innych niż dominująca grup etnicznych. Zatem pojawia się pytanie, jak różne aspekty nierówności wpływają na codzienne doświadczenie osób niepełnosprawnych. W artykule zostaną podjęte kwestie rozumienia niepełnosprawności w różnych kulturach i wpływ tego rozumienia na podejmowane działania osób z niepełnosprawnością.

\section{Słowa kluczowe}

niepełnosprawność, różnice kulturowe, niepełnosprawność w kulturach.

\section{WSTĘP}

$\mathrm{M}$ imo iż niepełnosprawność jest zjawiskiem powszechnym i ponadczasowym, to jednak w różnych kręgach kulturowych i obszarach świata jest różnie, często odmiennie rozumiana (Striker 1999: 25). Niepełnosprawność może być postrzegana na wiele sposobów, w zależności od kultury, która wpływa na jej obraz oraz dopuszczalne sposoby postępowania wobec osób niepełnosprawnych (por. Scheer, Groce 1988; Miles 1995; Ingstat, Whyte 1995; Stone 1999, 2001). Należy podkreślić, że to, co w jednej kulturze uznawane jest za czynnik naznaczający i wykluczający, w innej może być kwestią neutralną lub wręcz może być oceniane pozytywnie (Ingstad, Whyte 1995). Samo pojęcie niepełnosprawności oraz reakcje społeczne na odmienność fizyczną, zmysłową lub psychiczną nie mają uniwersalnego charakteru; zależą one od ukształtowanego kulturowo i powszechnie podzielanego pojęcia „normalności”, które wyznacza granice akceptacji dla odmienności związanej z deficytami sprawności zmysłowej, fizycznej i psychicznej (Hanks, Hanks 1984). Niemal każda kultura kształtuje wzory i normy, tworząc określone ideały dla funkcjonowania ciała i umysłu (Barnes, Mercer 2008).Wszystko, co jest inne, podlega często wykluczeniu. Status społeczny osób niepełnosprawnych w znacznej mierze jest kształtowany przez kulturę oraz obecny w tych społeczeństwach dominujący systemy wierzeń (Devlieger 1995: 95). Tak rozumiana niepełnosprawność w znacznie mniejszym stopniu dotyczy kwestii fizycznych czy psychicznych jednostek, ale przede wszystkim ich relacji ze sprawną większością (Hunt 1966). Kultura wpływa więc na postrzeganie osób niepełnosprawnych i narzucaną im pozycję oraz przypisywane role w społeczeństwie. Pokazuje to, że niepełnosprawność 
jest zjawiskiem konstruowanym kulturowo. Niepełnosprawność jest wynikiem narzuconych kulturowo wzorów normalności, które dla tej kategorii są opresyjne. Ich siła wynika z podzielanej powszechnie tradycji (Goodley 2011). Duże znaczenie ma też obecny społeczeństwach dominujący systemy wierzeń (Devlieger 1995).

Badanie niepełnosprawności w perspektywie kulturowej i etnicznej staje się niezwykle istotne w dobie migracji na szeroką skalę. Jak pokazują badania Eurostatu, 1 stycznia 2018 r. w Unii Europejskiej mieszkało 22,3 mln obywateli państw trzecich, a w samym roku 2017 napływ nowych migrantów z krajów spoza UE wynosił 2,4 mln. Wśród osób spoza Unii, które nabyły obywatelstwo, 27\% (łącznej liczby przypadków nabycia obywatelstwa) pochodziło z Afryki, z Europy, spoza UE-28 - 21\%, z Azji - 21\%, z Ameryki Północnej i Południowej - 11\%. Do tego następują przepływy pomiędzy państwami w obrębie Unii. Dane te pokazują, że we współczesnym świecie odsetek ludzi migrujących jest względnie wysoki. Dotyczy to również Polski. W roku 2018 Polska wydała ponad 683 tys. pozwoleń na pobyt w naszym kraju obywateli spoza Unii Europejskiej, co sprawia, że jesteśmy obecnie liderem pod względem liczby udzielanych zezwoleń na pracę imigrantom (Eurostat 2018). Oznacza to, że również w Polsce pojawiają się lub będą się pojawiały osoby niepełnosprawne $\mathrm{z}$ różnych regionów świata. Osoby te zetkną się z rozumieniem niepełnosprawności, które jest zupełnie inne niż w ich kraju pochodzenia, również z innym podejściem do niepełnosprawności prezentowanym przez instytucje. Dodatkowo warto zwrócić uwagę, że w przypadku osób niepełnosprawnych pochodzących $\mathrm{z}$ innych kręgów kulturowych lub z innych niż dominująca grup etnicznych wystąpić może nakładanie się wykluczenia społecznego i różnych rodzajów dyskryminacji. Pojawia się zatem pytanie, jak różne aspekty nierówności wpływają na codzienne doświadczenie osób niepełnosprawnych. Kwestie etniczności jawią się tu jako szczególnie istotne i często dyskryminacja związana $\mathrm{z}$ tym wymiarem jest silniejsza niż ta związana $\mathrm{z}$ niepełnosprawnością. Wpływ kultury na życie osób niepełnosprawnych powinien być analizowany z dwóch perspektyw. Pierwszą kwestią, którą należy poddać analizie, jest wpływ doświadczenia migracji i pochodzenia $z$ innej niż dominująca grupy etnicznej na tożsamość osoby niepełnosprawnej, kolejną - to, jak zderzenie tych dwóch kultur będzie wpływało na podejmowane w kontekście własnej niepełnosprawności działania. Te dwie kwestie wydają się niezwykle istotne dla zrozumienia samego fenomenu niepełnosprawności w ujęciu kulturowym. Badania nad tożsamością osób niepełnosprawnych są kwestią niezwykle istotną i prowadzone są od dawna (por. Żuchowska-Skiba 2016). Sama tożsamość jest jednak bardzo złożonym konstruktem. Jak pokazują badania, nie wszyscy niepełnosprawni uważają się za niepełnosprawnych lub postrzegają własną niepełnosprawność jako kluczowy aspekt własnej tożsamości. Tożsamość osób może dynamicznie ewoluować, a zmiany te mogą wynikać z zakłóceń w ustalonych wzorcach życia codziennego, do czego dochodzi na przykład $\mathrm{w}$ wyniku migracji, a także $\mathrm{z}$ bardziej subtelnych zmian, które pojawiają się w miarę starzenia się ludzi lub przyjmowania nowych ról (Molly, Knight, Woodfield 2003). Dlatego zwrócenie uwagi na aspekt etniczności w badaniach nad tożsamością osób niepełnosprawnych wydaje się bardzo istotny. Podjęcie takich analiz jest również ważne w Polsce w kontekście pojawiających się nowych fal migracyjnych z różnych części świata. Do Polski coraz częściej przyjeżdżają osoby z Ukrainy, Bliskiego Wschodu, Afryki czy 
Wietnamu. Są to zarówno migranci zarobkowi, jak i uchodźcy, a wśród nich coraz częściej osoby niepełnosprawne. Przeprowadzenie badań dotyczących postaw i doświadczeń osób niepełnosprawnych z różnych grup, jak również ich postrzegania wykluczenia społecznego oraz własnych doświadczeń związanych $\mathrm{z}$ dyskryminacją i uprzedzeniami, w kontekście takich czynników jak pochodzenie etniczne, wiek, płeć i orientacja seksualna, jest coraz bardziej potrzebne. Badania pokazują, że ze wszystkich aspektów tożsamości osób niepełnosprawnych mieszkających $\mathrm{w}$ środowiskach zróżnicowanych pod względem etnicznym osoby te - mówiąc o swej tożsamości - najczęściej podkreślały kwestie związane z ich własnym pochodzeniem jako te budujące ich tożsamość.

Źródła tożsamości etnicznej obejmowały: kraj urodzenia rodziców, kraj stałego pobytu, przynależność osobistą do obszaru regionalnego w kraju urodzenia/pobytu, używanie wspólnego języka, członkostwo w społeczności religijnej lub wyznaniowej i rasę lub kolor (Molly, Knight, Woodfield 2003).

Dlatego też niezwykle istotna wydaje się naukowa analiza sposobów patrzenia na niepełnosprawność obecnych w różnych kulturach, zwrócenie uwagi na wierzenia, które wpływają na przeżywanie niepełnosprawności i radzenie sobie z nią, praktyki kulturowe czy potrzeby wynikające z przynależności do konkretnej kultury w grupach etnicznych czy mniejszościowych. Różnice kulturowe będą dotyczyć definiowania samego terminu zdrowie, ale również będą one dotyczyły sposobu, $w$ jaki postrzegane są problemy zdrowotne i sposoby radzenia sobie z nimi. Dodatkowo, co nie mniej istotne, różnice międzykulturowe będą wpływały na gotowość do poszukiwania pomocy, stosowanie się do zaleceń lekarzy i innych specjalistów związanych z rehabilitacją, a także na samokontrolę (Matsumoto, Juang 2007). Wzięcie pod uwagę etniczności w badaniach nad niepełnosprawnością pozwala zrozumieć zachowanie, podejmowanie decyzji przez osoby niepełnosprawne, nie zapominając oczywiście o cechach jednostkowych i autonomii każdego człowieka. Napięcie między starymi i nowymi normami w życiu migranta zawsze jest zjawiskiem trudnym, dodatkowo w przypadku osób niepełnosprawnych zderzają się ze sobą stare i nowe idee dotyczące niepełnosprawności (Stone 2005). Szok kulturowy, różnice językowe, zmiana systemu wartości jednostki i rodziny, oczekiwania wobec roli, inny status społeczny i ekonomiczny niż w kraju pochodzenia - będą dla migranta wyzwaniem. Zjawiska te będą odczuwane znacznie silniej przez osoby, które musiały zmienić swe miejsce zamieszkania nie ze względu na własne chęci, a ci, którzy dodatkowo muszą zmagać się z niepełnosprawnością, będą te napięcia odczuwać jeszcze silniej. Zatem niezwykle ważna staje się umiejętność zrozumienia i możliwość odpowiedniego zareagowania na potrzeby i obawy jednostek z niepełnosprawnością i ich rodzin pochodzących z mniejszości etnicznych lub z grup mniejszościowych czy ze społeczności migrantów, tak by zrozumieć pewne praktyki kulturowe.

\section{NIEPEŁNOSPRAWNOŚĆ W KULTURACH}

Różnice w odczuwaniu i przeżywaniu, a co za tym idzie radzeniu sobie z własną niepełnosprawnością, w zależności od kultury pochodzenia będą bardzo różnorodne. Jak wskazuje Matsumoto i Juang (2007) kultura bardzo wyraźnie określa przekonania i postawy 
jednostki wobec zdrowia, choroby czy niepełnosprawności, wpływając na rozumienie takich kwestii, jak sama definicja zdrowia, spostrzeganie własnego ciała, atrybucje przyczyn chorób. Ważne z tej perspektywy wydają się również takie kwestie jak umiejscowienie poczucia kontroli, przestrzeganie zaleceń lekarskich, poszukiwanie pomocy oraz rola sieci społecznych i udzielane wsparcie. Kwestie te będą różnie rozumiane w różnych kulturach i można je analizować poprzez różne wymiary kultury. Najważniejszymi wymiarami wydają się być indywidualizm i kolektywizm, ale ważne będą również dystans władzy, męskość versus kobiecość oraz skłonność do unikania niepewności (Hofstede 2000). W niektórych językach w ogóle nie pojawia się słowo niepełnosprawny. Społeczeństwa często grupują jednostki posiadające wspólne odmienności (np. niewidomi, głusi) i w różny sposób te niepełnosprawności nazywają, w zależności od interpretacji konkretnej niepełnosprawności. W większości społeczeństw osoby niepełnosprawne są uznawane za różne od większości populacji. Ta sama grupa większościowa może przyznawać różne znaczenie różnym niepełnosprawnościom. Może jedne doceniać, innych nie zauważając lub dyskryminując - przykładowo osoby niewidzące mogą być włączone do społeczeństwa i mogą otrzymywać adekwatną pomoc, a osoby z niepełnosprawnością intelektualną mogą być zostawione same sobie (Stone 2005). Zatem analizie należy poddać różne kategorie kulturowe, które będą wpływały na możliwość udziału osób niepełnosprawnych w życiu społecznym.

Przykładem takich kwestii będzie umiejscowienie przyczyny niepełnosprawności, wartościowanie cech niepełnosprawności i antycypowane role osób niepełnosprawnych (Groce 2005). Przekonania religijne lub szerzej kulturowe dotyczące przyczyn niepełnosprawności pomagają przewidywać, jak będą traktowane w danej kulturze jednostki z niepełnosprawnością. Przykładowo - pojawienie się w rodzinie dziecka z niepełnosprawnością może być rozumiane $\mathrm{w}$ różnych kulturach jako dowód boskiego gniewu lub kazirodztwa, niewierności, dowód tzw. złej krwi czy też pech lub przeznaczenie (Groce, Zola 1993; Ingstad 1990). W wielu religiach pojawia się niepełnosprawność jako nieszczęście zesłane przez Boga, los, karma, często widziana jest też jako kara za grzechy własne lub przodków (por. Goodley 2011; Miles 1995: 22; Żuchowska-Skiba 2016: 5455). Pojawienie się niepełnosprawności na późniejszym etapie życia może być tłumaczone jako kara boska dla tej konkretnej jednostki. W takim rozumieniu osoba doświadczająca niepełnosprawności, która jest wynikiem np. działania osób trzecich, nie będzie traktowana jako niewinna ofiara. Wiele wierzeń ludowych obarcza odpowiedzialnością osobę niepełnosprawną, sugerując, że popełniła „wykroczenie przeciwko własnemu duchowi”. Zatem osoba taka może być obiektem ostracyzmu lub dyskryminacji ze względu na strach, że mogłaby sprowadzić nieszczęście na innych (Groce 2005). W różnych religiach i wierzeniach często odnajdujemy kwestie związane z niepełnosprawnością. Przykładowo, niepełnosprawność widziana przez islam nie jest stygmatem, nie powinna być odrzucana jako nieczysta czy uznana za dzieło szatana. Jest ona postrzegana jako naturalne kontinuum ludzkiego zdrowia. Nie jest również widziana jako kara pochodząca od Boga. Zatem koncept islamski w sposób zasadniczy różni tę perspektywę religijną od innych religii, w tym również monoteistycznych (Autorka 2017). Wyjątkowo trudno jest osobom niepełnosprawnym w społeczeństwach wierzących $w$ reinkarnację, gdyż 
ich obecna sytuacja jest uznawana za zasłużoną, zatem pojawia się mniejsza sympatia i mniejsza chęć niesienia pomocy. W niektórych społecznościach pokutuje również przekonanie, że niepełnosprawnością można się zarazić np. przez złe spojrzenie lub dotyk. Przede wszystkim według wierzeń ludowych kobiety w ciąży powinny unikać kontaktu $\mathrm{z}$ osobami niepełnosprawnymi. Ta idea była odnotowywana w badaniach nad niepełnosprawnością w różnych grupach migrantów w Wielkiej Brytanii (Groce 2005).

Nie wszystkie przekonania dotyczące niepełnosprawności są negatywne. W swych badaniach Madrios pokazał wiarę Amerykanów meksykańskiego pochodzenia w to, iż niepełnosprawność dziecka jest wolą Bożą, ponieważ konkretna liczba dzieci ma urodzić się z niepełnosprawnością. Bóg wybiera zatem rodziców, którzy będą dobrzy i opiekuńczy wobec dziecka z niepełnosprawnością i podołają tej specjalnej roli (Mardiros 1989).

W kontekście kulturowym niepełnosprawność przecina się z wieloma innymi wymiarami nierówności, wykluczenia, a także praktykami i wierzeniami. Kombinacja tych wielu czynników wpływa na to, co w danym społeczeństwie będzie uważane za atrakcyjne, a co będzie podlegać wykluczeniu, czego przykładem może być wpływ płci na potęgowanie wykluczenia. $\mathrm{W}$ wielu społecznościach migrantów posiadanie syna jest niezwykle ważne i jest dla rodziny wyznacznikiem miejsca w strukturze i zabezpieczeniem własnej egzystencji w przyszłości, zatem ponoszenie kosztów edukacji czy zaawansowanej opieki medycznej lub zajęć dodatkowych dla dziewczynek z niepełnosprawnością może być traktowane jako mniej istotnie niż ponoszenie tych kosztów w przypadku niepełnosprawnych chłopców. Ważnym czynnikiem w badaniach kulturowych nad niepełnosprawnością jest również zwrócenie uwagi na to, jaką potencjalnie rolę będzie pełniła dorosła osoba niepełnosprawna (Groce 2005). Podstawową determinantą pozytywnego stosunku do ponoszenia kosztów integracji osób niepełnosprawnych ze społeczeństwem jest to, w jaki sposób dane społeczeństwo widzi rolę dorosłej osoby niepełnosprawnej. Pełna rola zawiera nie tylko możliwość pracy, ale również zawarcie małżeństwa, stworzenie rodziny, życia na własną rękę, decydowania o sobie, partycypację w życiu obywatelskim, religijnym, w rekreacji. Społeczeństwa różnią się między sobą w sposobie odgrywania tej roli, natomiast zasadniczą kwestią jest, czy osoba niepełnosprawna uczestniczy w jej odgrywaniu w porównywalnym stopniu do osób pełnosprawnych, oczywiście przy założeniu, ze pochodzi z kategorii społecznych porównywalnych pod względem statusu społeczno-ekonomicznego. Przekonania dotyczące przyczyny niepełnosprawności i oczekiwań wobec roli dorosłego niepełnosprawnego nie występują w izolacji. Wpływa na nie wiele czynników, jednakże badacze tego zjawiska wskazują na trzy podstawowe determinanty, poprzez które kultura wpływa na oczekiwania wobec roli osoby niepełnosprawnej, czyli rolę rodziny, rolę społeczności oraz rolę personelu profesjonalnego (Groce 2005).

Mimo że w społeczeństwach zachodnich dominuje model rodziny nuklearnej, to jednak poza tym kręgiem kulturowym sytuacja wygląda inaczej. Wyraźnie widać, że w społecznościach migrantów nadal dominuje model rodziny wielopokoleniowej i rozszerzonej. To taki typ rodziny determinuje życie, pracę, małżeństwo i nawet miejsce, gdzie szuka się opieki zdrowotnej. Często jest to wyraźnie sprzeczne z procesem rehabilitacji i usługami dla osób niepełnosprawnych, których głównym celem jest wspieranie samo- 
dzielności tych osób. Ściśle połączone wewnętrznie społeczności migrantów nie tylko dostarczają wsparcia osobom niepełnosprawnym, ale również nadzorują sposób, w jaki osoby te radzą sobie $\mathrm{z}$ własną sytuacją oraz to, w jaki sposób rodziny odpowiadają na potrzeby osób niepełnosprawnych. Przykładem jest kwestia pracy osób niepełnosprawnych. W niektórych społeczeństwach praca osób niepełnosprawnych będzie kwestią bardzo pożądaną i będzie stanowiła element terapii i dawała możliwość samorealizacji. Natomiast w innych grupach mniejszościowych praca osób niepełnosprawnych jest dla rodziny powodem wstydu, ponieważ jest symbolem wykorzystywania niepełnosprawnego członka rodziny i braku akceptacji. W skrajnych przypadkach jest podstawą do utraty przez rodzinę honoru. Nawet jeśli rodzina rozumie znaczenie wspierania do samodzielności, to musi poradzić sobie z krytyką i zarzutami ze strony społeczności, w której żyje (Ingstad 1990).

\section{STOSUNEK DO PERSONELU MEDYCZNEGO}

Kultura wpływa również na sposób, w jaki osoby niepełnosprawne i ich rodziny współpracują z profesjonalistami świadczącymi np. usługi rehabilitacyjne dla osób niepełnosprawnych. W mocno zhierarchizowanych społeczeństwach niezwykle ważne będzie miejsce, jakie specjaliści zajmują w hierarchii społecznej. Gdy będą uznawani za przedstawicieli klasy wyższej, ich słowa będą miały wielkie znaczenie, co oczywiście będzie wpływało na kontakt $\mathrm{z}$ osobą niepełnosprawną i jej rodziną. W innym typie społeczeństwa, gdzie profesjonaliści jako pracownicy najemni nie są przez ludzi pochodzących z klasy wyższej poważani, komunikacja taka może być utrudniona. Badacze zjawiska pokazują przykłady bogatych członków rodzin, które życzą sobie rozmawiać jedynie z osobami postawionymi najwyżej w strukturze placówki, i najczęściej chodzi o mężczyznę na najwyższym szczeblu drabiny (Groce 2005). W przypadku migrantów kultura będzie miała również wpływ na dostęp do wsparcia, z jakiego potencjalnie mogą skorzystać osoby niepełnosprawne. Badania przeprowadzone w Wielkiej Brytanii wyraźnie pokazały, że proces identyfikowania i uzyskiwania dostępu do wsparcia dla osób niepełnosprawnych był przez migrantów z niepełnosprawnościami postrzegany jako zbyt skomplikowany i czasochłonny, do tego stopnia, że niektórzy niepełnosprawni w ogóle rezygnowali z udziału w tym procesie. Czynnikiem, który dodatkowo zaostrzył trudności były bariery językowe. Dostępne informacje na temat usług i wsparcia dla osób niepełnosprawnych były rutynowo krytykowane. Ludzie zgłaszali, że nie są w stanie ustalić, jakie lokalne usługi były dla nich dostępne. Jest to ważna kategoria do analizy w społeczeństwie polskim, gdzie znajomość języków obcych - choć z roku na rok lepsza - nie jest dobra i pracownicy zatrudnieni w sektorze usług np. rehabilitacyjnych oferowanych przez państwo najczęściej słabo znają języki. Jak pokazują badania, korzystanie z usług rehabilitacyjnych przez mniejszości etniczne jest niezadawalające (Aloneftis 2013). Niski poziom korzystania z nich wynika m.in. z braku zrozumienia zachowań np. profesjonalistów w kulturze przyjmującej (Griner i Smith 2006), poziomu akulturacji kulturowej niepełnosprawnych migrantów lub ich rodzin (Frey i Roysircar 2006; Kim i Omizo 2006), barier językowych, braku 
dostępnych informacji (Hubert 2006). Na ową niechęć będą również wpływały wcześniejsze negatywne doświadczenia. Brak jest również badań eksplorujących drugą stronę procesu rehabilitacji, czyli personelu medycznego. Badania Rebekki Aloneftis pokazują, że pracownicy służby zdrowia wykazują spolaryzowane myślenie na temat różnorodności; z jednej strony to coś, czego należy się obawiać, ale z drugiej wzbudza ich ciekawość. Dychotomicznie opisują różnorodność jako dobrą lub złą. Tak więc jeśli pracownicy służby zdrowia postrzegają różnorodność $\mathrm{w}$ kategoriach dychotomicznych, może być mniej prawdopodobne, że spróbują osiągnąć porozumienie z klientami zróżnicowanymi etnicznie, uznając różnorodność jako coś, co może powodować nieprzyjemne uczucia, takie jak strach i niepokój, ale także coś, co wzbudza podekscytowanie i zainteresowanie, umożliwia pracownikom służby zdrowia krytyczne podejście do zrozumienia, co jest oczywiste. Może pozwolić im wziąć pod uwagę złożoność związaną z różnorodnością i zaakceptować fakt, że decyzje są bardzo zależne od kontekstu, który jest nieuchronnie uwarunkowany historycznie i kulturowo (Stuart 2004). Każdy przypadek powinien być postrzegany w unikalnym kontekście, w którym jest osadzony. Dotyczy to nie tylko bezpośredniego otoczenia klienta z mniejszości etnicznej, ale także otaczających go szerszych struktur społeczno-politycznych. Badania przeprowadzane na reprezentantach różnych grup etnicznych pokazują ważną rolę rodziny i społeczności lokalnej w leczeniu i rehabilitacji związanej z różnymi problemami. W terapii dostosowanej do potrzeb konkretnej kultury powinni uczestniczyć członkowie bliższej i dalszej rodziny, ponieważ często problemy tkwią nie tylko w poszczególnych jednostkach i np. ich podejściu do rehabilitacji, ale w „zbiorowym układzie jednostek” i powiązanych z nimi czynnikach społecznych (Matsumoto, Juang 2007: 227).

\section{TERAPIA KULTUROWO ADEKWATNA}

Badania nad postrzeganiem przez personel medyczny wrażliwej na kulturę opieki nad osobami niepełnosprawnymi są nadal nieliczne. W literaturze pojawiają się pojęcia terapii kulturowo adekwatnej oraz wrażliwości kulturowej podczas współpracy z osobą niepełnosprawną pochodzącą z odrębnego od dominującego kręgu kulturowego. W jednym z niewielu takich badań Summer i Jones (2004) badali stosowność kulturową usług skierowanych do osób z trudnościami w uczeniu się pochodzących $\mathrm{z}$ innej niż dominująca grupy etnicznej. Zidentyfikowali oni konflikt między wartościami służącymi indywidualności, wyborem i normalizacją a wartościami innych religii i kultur. Bariery utrudniające dostęp do różnego rodzaju usług i aktywności obejmują nieznajomość języka, brak świadomości przekonań kulturowych i religijnych oraz ograniczenia budżetowe (Hammerton 2006). Coraz częściej w literaturze można znaleźć wskazówki, by realizowane programy skierowane do osób niepełnosprawnych były kulturowo wrażliwe (culturally sensitive) lub kulturowo odpowiednie (culturally appropriate) (Coleridge 1993). Kwestie kulturowe muszą być brane pod uwagę przy projektowaniu i implementowaniu czy wykonywaniu działań skierowanych do osób żyjących z niepełnosprawnością w społeczności mniejszościowej (Stone 2005). 
Analiza wpływu kultury na proces rozumienia niepełnosprawności ma bardzo wiele etapów. Jest to zamierzenie stosunkowo trudne ze względu na wiele wątków, które mogą być podjęte - począwszy od badania tożsamości osób niepełnosprawnych pochodzących $\mathrm{z}$ innych kultur lub grup etnicznych, poprzez badanie samej kultury, systemów wierzeń, które determinują, jak niepełnosprawność jest rozumiana w różnych kręgach kulturowych aż po relacje między osobami niepełnosprawnymi a personelem medycznym. W dzisiejszym świecie, gdzie coraz częściej ludzie doświadczają uchodźctwa lub migracji, ważne wydaje się badanie zderzenia dwóch systemów patrzenia na niepełnosprawność. Zdaniem Anselma Straussa badanie przemian tożsamości, tego jak są postrzegane i interpretowane oraz sposobów rozumienia siebie i własnego życia można ukazać najpełniej dzięki narracjom biograficznym (1959: 96). Dlatego do zbadania tożsamości imigrantów i imigrantek z niepełnosprawnością mieszkających w Polsce można posłużyć się biograficznymi wywiadami narracyjnymi. Metoda ta pozwala na zebranie danych pozwalających na analizę procesu zmiany tożsamości, umożliwiając odtworzenie procesualnej logiki zdarzeń, które wpłynęły na obraz samych siebie badanych i w konsekwencji ukształtowały ich tożsamość (Hermanns 1987).

Centralną kategorią analizy stanowi w takim przypadku kategoria trajektorii rozumiana tu zarówno jako doświadczenie biograficzne, jak i specyficzny typ procesu społecznego. Umożliwiła ona zrozumienie procesów ustrukturowanych przez łańcuch powiązanych ze sobą zdarzeń biograficznych, będących powodem załamań, oczekiwań oraz poczucia utraty. Zachodzących pod wpływem zewnętrznych wydarzeń w ciągu życia jednostki, które pozostawały poza jej kontrolą i były dla niej źródłem swoistego cierpienia (Riemann, Schütze 1992). Trajektorie losów imigrantów z niepełnosprawnościami powinny zostać odtworzone na podstawie ich narracji biograficznych zorientowanych wokół trzech kluczowych okresów ich życia. Pierwszy obejmuje życie w kraju rodzinnym, który ukształtował ich tożsamość w oparciu o tradycje i wartości płynące z rodzimych norm i wierzeń. Drugi - poprzedzony decyzją o opuszczeniu kraju - związany był z przybyciem do kraju przyjmującego i zderzeniem z odmienną kulturą oraz ocenami imigrantów w opinii społeczeństwa przyjmującego. Sytuacja ta stanowi punkt zwrotny, który wymaga od imigrantów negocjowania swoich tożsamości w nowej rzeczywistości społeczno-kulturowej państwa przyjmującego. Trzeci okres, związany z decyzją o pozostaniu na emigracji, stanowi czas, gdy tożsamość niepełnosprawnych migrantów będzie ulegała zmianom w wyniku adaptacji do rzeczywistości kulturowo-społecznej pod wpływem konieczności dynamicznego reagowania na nowe dla nich sytuacje.

\section{PODSUMOWANIE}

Badanie wpływu kultury na sytuację niepełnosprawnych osób żyjących w środowiskach zróżnicowanych pod względem kulturowym i etnicznym nie jest zadaniem prostym. W artykule zostały przedstawione różne perspektywy badawcze, które mogą zostać podjęte. 
Samo zjawisko nabiera znaczenia ze względu na coraz częstsze występowanie migracji i konieczności życia w nowym środowisku, gdzie pojawiają się nowe normy i tożsamości. Doświadczenia osób niepełnosprawnych w warunkach migracji są nadal dość słabo zbadane, mimo iż kwestie związane $\mathrm{z}$ kulturowo adekwatną terapią i działaniem wrażliwym kulturowo wydają się dziś podstawą.

\section{BIBLIOGRAFIA}

Aloneftis, Rebecca (2013). Health Professionals' Perceptions on Care Practice with Learning Disability Ethnic Minority Clients: a Qualitative Study. Praca nieopublikowana, https://www.researchgate.net/publication/256845934_Health_professionals\%27_perceptions_on_care_practice_with_learning_disability_ethnic_minority_clients_a_qualitative_study (dostęp: 20.10.2019).

Barnes, Colin, Mecer, Geof (2008). Niepetnosprawność. Warszawa: Sic.

Coleridge, Peter (1999). Development, Cultural Values and Disability: The example of Afghanistan. W: Emma Stone (red.). Disability and Development: Learning from action and research on disability in the majority world. Leeds: The Disability Press, s. 149-167.

Devlieger, Paul (1995). Why Disabled? The cultural Undrstanding of Phisical Disability in an African Society. W: Benedict Ingstad, Susan R. Whyte (red.). Disability and Culture. Berkley: University of California Press, s. 94-106.

Eurostat Migration and migrant population statistics. https://ec.europa.eu/eurostat/ statistics-explained/index.php?title=Migration_and_migrant_population_statistics/ pl\#Populacja_migrant.C3.B3w:_w_dniu_1_stycznia_2018_r._w_UE_mieszka.C5.82o _22.2C3_mln_obywateli_pa.C5.84stw_trzecich (dostęp: 28.10.2019).

Eurostat (2018). Newsrelease 166/2018. https://ec.europa.eu/eurostat/documents/2995521/ 9333446/3-25102018-AP-EN.pdf/3fa5fa53-e076-4a5f-8bb5-a8075f639167 (dostęp: 28.10.2019).

Frey, Melissa, Roysircar, Gargi (2006). South and East Asian International Students' Perceived Prejudice, Acculturation, and Frequency of Help Resource Utilization. „Journal of Multicultural Counseling and Development", 34, s. 208-222.

Goodley, Dan (2011). Disability studies. An Interdisciplinary Introduction. London: Sage.

Griner, Derek, Smith, Timothy B. (2006). Culturally Adapted Mental Health Intervention: A Meta-analytic Review. „Psychotherapy: Theory, Research, Practice, Training”, 43, s. 531-548.

Groce, Nora (2005). Immigrants Disability and Rehabilitation. W: John H. Stone. Culture and Disability: Providing Culturally Competent Services (Multicultural Aspects of Counseling And Psychotherapy). Thousand Oaks, London, New Delphi: Sage Publications, s. 1-14.

Groce, Nora, Zola, Irving Kenneth (1993). Multiculturalism, Chronic Illness and Disability. „Pediatrics”, 91(5), s. 1048-1055. 
Hanks, Jane R., Hanks, Lucien M. (1948). The Physically Handicapped in Certain Non-Occidental Societies. „Journal of Social Issues”, 4(4), s. 11-20.

Hermanns, Harry (1987). Narrative Interview - a New Tool for Sociological Field Research. W: Zbigniew Bokszanski, Marek Czyzewski (red.). Approaches to the Study of Face to Face Interaction. „Folia Sociologica”, 13, s. 43-56.

Hofstede, Geert (2000). Kultury i organizacje: zaprogramowanie umysłu. Warszawa: Polskie Wydawnictwo Ekonomiczne.

Hubert, Jane (2006). Family Carers' Views of Services for People with Learning Disabilities from Black and Minority Ethnic Groups: a Qualitative Study of 30 Families in a South London Borough. „Disability \& Society”, vol. 21, no. 3, May 2006, s. 259-272.

Hunt, Paul (1966). Stigma: The Experience of Disability. London: Geoffrey Chapman.

Ingstad, Benedict (1990). The Disabled Person in the Community: Social and Cultural Aspects. „I nternational Journal of Rehabilitation Research”, 13, s. 187-194.

Ingstad, Benedict, Whyte, Suzan Reynolds (1995). Disability and Culture. Berkeley: University of California Press.

Kim, Bryan K., Omizo, Michael M. (2006). Behavioral Acculturation and Enculturation and Psychological Functioning among Asian American College Students. „Cultural Diversity \& Ethnic Minority Psychology", 12, s. 245-258.

Mardiros, Marylin (1989). Conception of Childhood Disability among Mexican-American Parents. „Medical Antropology”, 12, s. 55-68.

Matsumoto, David, Juang, Linda (2007). Psychologia międzykulturowa. Gdańsk: Gdańskie Wydawnictwo Psychologiczne.

Miles, Margaret (1995). Disability in an Eastern Religious Context: Historical Perspectives. „Disability and Society”, 10(1), s. 49-69.

Molly, Donna, Knight, Tim, Woodfield, Kandy (2003). Diversity in Disability: Exploring the Interactions Between Disability, Ethnicity, Age, Gender and Sexuality. Department for Work and Pension, Leeds: Corporate Document Services. www.dwp.gov.uk/asd/ (dostęp: 10.10.2019).

Riemann, Gerhard, Schütze, Fritz (1991). Trajectory As a Basic Theoretical Concept for Analysing Suffering and Disorderly Social Processes. W: David R. Maines (red.). Social Organization and Social Processes. Essays in Honor of Anselm Strauss. New York: Adeline de Gruyter, s. 333-356.

Scheer, Jessica, Groce, Nora (1988). Impairment as a Human Constant: Cross-Cultural and Historical Perspectives on Variation. „Journal of Social Issues”, 1(44), s. 23-37.

Stojkow, Maria, Żuchowska-Skiba, Dorota (2017). Niepełnosprawność w Islamie. W: Jakub Niedbalski, Mariola Racław, Dorota Żuchowska-Skiba (red.). Oblicza niepełnosprawności w teorii i praktyce. Łódź: Wydawnictwo Uniwersytetu Łódzkiego, s. 323-326.

Stone, Emma (1999). Disability and Development in the Majority World. W: Emma Stone (red.). Disability and Development: Learning from Action and Research on Disability in the Majority World. Leeds: Disability Press, s. 1-18. 
Stone, Emma (2001). A Complicated Struggle: Disability, Survival and Social Change in a Majority Word. W: Mark Priestley (red.). Disability and the Life Course: Global Perspectives. Cambridge: Cambridge University Press, s. 50-64.

Stone, John H. (2005). Culture and Disability: Providing Culturally Competent Services (Multicultural Aspects of Counseling And Psychotherapy). Thousand Oaks, London, New Delphi: Sage Publications.

Strauss, Anselm (1959). Mirrors and Masks. Glencoe, IL: Free Press.

Strauss, Anselm (1995). Identity, Biography, History, and Symbolic Representations. „Social Psychology Quarterly”, vol. 58, no. 1, 1995, s. 4-12.

Striker, Henri-Jacques (1999). A History of Disability. Ann Arbor: The University of Michigan Press.

Summers, S.J. and Jones, J. (2004). Cross-cultural Working in Learning Disabilities Services: Clinical Issues, Dilemmas and Tensions. „Journal of Intellectual Disabilities Research", 48(7), s. 687-694.

Zoebia, Ali, Qulsom, Fazil, Bywaters, Paul, Wallace, Louise, Gurnam, Singh (2001). Disability, Ethnicity and Childhood: a Critical Review of Research. „Disability \& Society”, 16(7), s. 949-968.

Żuchowska-Skiba, Dorota (2016). Aktywność środowisk osób niepełnosprawnych we wspótczesnej Polsce. Warszawa: IFIS PAN. 